Virginia Commonwealth University vCU Scholars Compass

2014

\title{
The viability of aluminum Zintl anion moieties within magnesium-aluminum clusters
}

Haopeng Wang

Johns Hopkins University

Yeon Jae Ko

Johns Hopkins University

Xinxing Zhang

Johns Hopkins University

See next page for additional authors

Follow this and additional works at: http://scholarscompass.vcu.edu/phys_pubs

Part of the Physics Commons

Wang, H., Ko, Y., Zhang, X., et al. The viability of aluminum Zintl anion moieties within magnesium-aluminum clusters. The Journal of Chemical Physics, 140, 124309 (2014). Copyright (C) 2014 AIP Publishing LLC.

\section{Downloaded from}

http://scholarscompass.vcu.edu/phys_pubs/105

This Article is brought to you for free and open access by the Dept. of Physics at VCU Scholars Compass. It has been accepted for inclusion in Physics Publications by an authorized administrator of VCU Scholars Compass. For more information, please contact libcompass@vcu.edu. 
Authors

Haopeng Wang, Yeon Jae Ko, Xinxing Zhang, Gerd Gantefoer, Hansgeorg Schnoeckel, Bryan W. Eichhorn, Puru Jena, Boggavarapu Kiran, Anil K. Kandalam, and Kit H. Bowen Jr. 


\title{
The viability of aluminum Zintl anion moieties within magnesium-aluminum clusters
}

\author{
Haopeng Wang, ${ }^{1}$ Yeon Jae Ko, ${ }^{1}$ Xinxing Zhang, ${ }^{1}$ Gerd Gantefoer,${ }^{1}$ \\ Hansgeorg Schnoeckel, ${ }^{2}$ Bryan W. Eichhorn, ${ }^{3}$ Puru Jena, ${ }^{4}$ Boggavarapu Kiran, ${ }^{5, a)}$ \\ Anil K. Kandalam, ${ }^{6, a)}$ and Kit H. Bowen Jr. ${ }^{1, a)}$ \\ ${ }^{1}$ Department of Chemistry, Johns Hopkins University, Baltimore, Maryland 21218, USA \\ ${ }^{2}$ Institute of Inorganic Chemistry, Karlsruhe Institute of Technology, 76128 Karlsruhe, Germany \\ ${ }^{3}$ Department of Chemistry, University of Maryland, College Park, Maryland 20742, USA \\ ${ }^{4}$ Department of Physics, Virginia Commonwealth University, Richmond, Virginia 23284, USA \\ ${ }^{5}$ Department of Chemistry, McNeese State University, Lake Charles, Louisiana 70609, USA \\ ${ }^{6}$ Department of Physics, West Chester University, West Chester, Pennsylvania 19383, USA
}

(Received 6 December 2013; accepted 6 March 2014; published online 24 March 2014)

\begin{abstract}
Through a synergetic combination of anion photoelectron spectroscopy and density functional theory based calculations, we have investigated the extent to which the aluminum moieties within selected magnesium-aluminum clusters are Zintl anions. Magnesium-aluminum cluster anions were generated in a pulsed arc discharge source. After mass selection, photoelectron spectra of $\mathrm{Mg}_{\mathrm{m}} \mathrm{Al}_{\mathrm{n}}{ }^{-}$ $(\mathrm{m}, \mathrm{n}=1,6 ; 2,5 ; 2,12$; and 3,11$)$ were measured by a magnetic bottle, electron energy analyzer. Calculations on these four stoichiometries provided geometric structures and full charge analyses for the cluster anions and their neutral cluster counterparts, as well as photodetachment transition energies (stick spectra). Calculations revealed that, unlike the cases of recently reported sodium-aluminum clusters, the formation of aluminum Zintl anion moieties within magnesiumaluminum clusters was limited in most cases by weak charge transfer between the magnesium atoms and their aluminum cluster moieties. Only in cases of high magnesium content, e.g., in $\mathrm{Mg}_{3} \mathrm{Al}_{11}$ and $\mathrm{Mg}_{2} \mathrm{Al}_{12}{ }^{-}$, did the aluminum moieties exhibit Zintl anion-like characteristics. (C) 2014 AIP Publishing LLC. [http://dx.doi.org/10.1063/1.4869104]
\end{abstract}

\section{INTRODUCTION}

The discovery of fullerenes ${ }^{1}$ and met-cars ${ }^{2,3}$ led scientists to search for unusually stable (magic) clusters that can potentially act as building blocks for novel materials. One such cluster is $\mathrm{Al}_{13}{ }^{-}$, it being stabilized by both its geometric structure and its 40-electron closed-shell. ${ }^{4,5} \mathrm{An}$ assembly of highly stable anionic clusters with counter-cations might form an ionic crystal lattice with high cohesive energy. For example, $\mathrm{KAl}_{13}$, a simple ionic "molecule" of $\mathrm{K}^{+}$and $\mathrm{Al}_{13}{ }^{-}$analogous to an alkali halide salt, was first theoretically predicted $^{6-8}$ and then experimentally confirmed ${ }^{9-11}$ to exhibit ionic character. Thus, $\mathrm{KAl}_{13}$ is potentially a building block of an ionic lattice.

Electrostatic interactions between ions are the major contributors to the stabilization of ionic lattices. A larger cohesive energy can be achieved when the ions are multiply charged. Therefore, ionic lattices containing multiply charged cluster ions are expected to have higher lattice stabilization energies compared to those containing singly charged ones. Zintl anions, the family of multiply charged polyatomic anions formed by main group elements, are potential building blocks for such ionic materials. Zintl anions were first systematically studied $^{12-15}$ in 1930s, while the term "Zintl phase" was first applied by Laves ${ }^{16}$ to the binary compounds formed between

\footnotetext{
a) Authors to whom correspondence should be addressed. Electronic addresses: kiran@mcneese.edu; akandalam@wcupa.edu; and kbowen@jhu.edu
}

the alkali or alkaline earth elements and the elements from Group 14. The definition of Zintl phase was later expanded to solids and "melts" formed by Zintl anions and highly electropositive elements, such as alkali metals. ${ }^{17}$ When combined with proper cations, Zintl anions can form ionic salts. ${ }^{18}$ Note that the Zintl phases have been observed mostly in solids.

In more recent times, the feasibility of forming Zintl anions in gas-phase clusters has become the focus of both experimental and theoretical studies. These clusters consist of multiply charged anionic moieties and their cationic neighbors. There have been several studies of Zintl cluster systems among the metalloids. For example, in one of the earliest experimental studies, the presence of the $\mathrm{Bi}_{3}{ }^{3-}$ Zintl anion was inferred from the observation of $\left(\mathrm{Na}_{4} \mathrm{Bi}_{3}\right)^{+}$as a magic cluster in mass spectra. ${ }^{19,20}$ Also, in joint experimental and theoretical studies of $\left(\mathrm{Na}_{4} \mathrm{Sn}_{4}\right)^{-},\left(\mathrm{NaGa}_{4}\right)^{-},\left(\mathrm{KSn}_{12}\right)^{-}$, and $\left(\mathrm{KPb}_{12}\right)^{-}$cluster anions, it was shown that their negatively charged group-III and group-IV moieties exhibited Zintl-characteristics. ${ }^{21-24}$

Even though anionic Zintl clusters of aluminum have not been reported in the solid state, one can gain insight into the possibility of forming aluminum-based Zintl phases by studying gas phase cluster systems. Such studies were motivated by the possibility of forming salt-like structures and/or by the desire to investigate unique bonding features. For example, the multiply charged aluminum cluster anions, $\mathrm{Al}_{4}{ }^{4-}$ and $\mathrm{Al}_{6}{ }^{2-}$, were shown to be present in $\left(\mathrm{MAl}_{4}\right)^{-}(\mathrm{M}=\mathrm{Li}$, 
$\mathrm{Na}, \mathrm{Cu}),{ }^{25}\left(\mathrm{Li}_{3} \mathrm{Al}_{4}\right)^{-},{ }^{26}$ and $\left(\mathrm{NaAl}_{6}\right)^{-}$[Ref. 27] cluster anions through combined anion photoelectron spectroscopic and theoretical studies. The stability of these multiply charged aluminum clusters was due to all-metal aromaticity (and antiaromaticity). Likewise, salt-like clusters were similarly explored in studies of $\left(\mathrm{LiAl}_{\mathrm{n}}\right)^{-},{ }^{28}\left(\mathrm{CuAl}_{\mathrm{n}}\right)^{-},{ }^{29}$ and $\mathrm{Al}_{13} \mathrm{M}^{-}$(M $=\mathrm{Li}, \mathrm{Na}, \mathrm{K}, \mathrm{Rb}$, and $\mathrm{Cs})^{30}$ cluster anions. In addition, the formation of bare, multiply charged $\mathrm{Al}_{n}{ }^{2-}$ and $\mathrm{Al}_{n}{ }^{3-}$ cluster anions by electron attachment to singly charged aluminum cluster anions has been reported, ${ }^{31}$ although the smallest observed sizes were $n=38$ and 103 , respectively.

Through anion photoelectron spectroscopy and theoretical calculations, we recently established the presence of aluminum Zintl anions within the sodium-aluminum clusters. ${ }^{32}$ Density functional theory (DFT) based calculations were carried out on both the neutral and negatively charged clusters, $\mathrm{Na}_{2} \mathrm{Al}_{6}, \mathrm{Na}_{4} \mathrm{Al}_{5}, \mathrm{Na}_{5} \mathrm{Al}_{5}, \mathrm{Na}_{3} \mathrm{Al}_{12}, \mathrm{Na}_{4} \mathrm{Al}_{12}$ and $\mathrm{Na}_{2} \mathrm{Al}_{6}{ }^{-}$, $\mathrm{Na}_{4} \mathrm{Al}_{5}{ }^{-}, \mathrm{Na}_{5} \mathrm{Al}_{5}{ }^{-}, \mathrm{Na}_{3} \mathrm{Al}_{12}{ }^{-}, \mathrm{Na}_{4} \mathrm{Al}_{12}{ }^{-}$, respectively. Calculations revealed not only that these clusters (in either their neutral or anionic charge states) are closed-shells according to the jellium-like shell model but also that the aluminum moieties in these clusters exhibit robust Zintl-character by carrying multiple charges as large as $-3.67 e$ in neutral $\mathrm{Na}_{5} \mathrm{Al}_{5}$ and $-3.43 e$ in neutral $\mathrm{Na}_{4} \mathrm{Al}_{12}$ clusters. Thus, these neutral sodium-aluminum clusters, with their enhanced stability (due to jellium-like shell closing) and the presence of zintlaluminum moieties, can potentially act as building blocks of cluster-assembled materials.

Motivated by our work on sodium-aluminum clusters and wishing to investigate the possibility of generating aluminum Zintl anion moieties using less electropositive elements, we have carried out a combined experimental and theoretical study on magnesium-aluminum neutral and anionic clusters. Determining the feasibility of forming aluminum Zintl anion moieties using magnesium cations as counter-ions is the main objective of this study. The choice of magnesium as the counter ion was partially motivated by the fact that magnesium has been shown to follow the jellium-like shell model as do sodium clusters. ${ }^{33,34}$ Note that in a recently reported study, specific sizes of $\mathrm{Mg}_{m} \mathrm{Al}_{n}{ }^{-}$cluster anions exhibited lower reactivity towards oxygen than their neighboring sizes. This was interpreted as being due to either spherical jellium-shell closings or geometrical distortions that led to crystal field-like splitting of subshells. ${ }^{35}$

Here, we report results from a mass spectrometric study of $\mathrm{Mg}_{\mathrm{m}} \mathrm{Al}_{\mathrm{n}}{ }^{-}$cluster anions, photoelectron spectroscopic measurements on the four most abundant cluster anions, i.e., $\mathrm{MgAl}_{6}{ }^{-}, \mathrm{Mg}_{2} \mathrm{Al}_{5}{ }^{-}, \mathrm{Mg}_{2} \mathrm{Al}_{12}{ }^{-}$, and $\mathrm{Mg}_{3} \mathrm{Al}_{11}{ }^{-}$, and supporting theoretical calculations. In these four stoichiometries, both 20 and 40 valence electron shell closings are present, in some cases for cluster anions and in others for their corresponding neutral clusters. Natural Population Analyses (NPA), i.e., charge analyses, were carried out for both neutral and anionic forms of all of these systems to explore the extent of Zintl anion character in the aluminum moieties of these magnesium-aluminum cluster systems. Also, a comparative study was conducted which focused on the similarities and differences between isoelectronic sodium-aluminum clusters and magnesium-aluminum clusters.

\section{METHODS}

\section{Experimental}

Negative ion photoelectron spectroscopy is conducted by crossing a mass-selected beam of anions with a fixedfrequency photon beam and energy analyzing the resultant photodetached electrons. The photodetachment process is governed by the energy conserving relationship, $h v=$ EBE + EKE, where $h v$ is the photon energy, EBE is the electron binding (photodetachment transition) energy, and EKE is the electron kinetic energy. Our apparatus has been described previously in Ref. 36. Briefly, the apparatus consists of an ion source, a linear time-of-flight (TOF) mass spectrometer, a Nd:YAG (yttrium aluminum garnet) photodetachment laser, and a magnetic bottle photoelectron spectrometer (MB-PES). The instrumental resolution of the MB-PES is $\sim 35 \mathrm{meV}$ at $1 \mathrm{eV}$ EKE. The third harmonic $(355 \mathrm{~nm}$, $3.493 \mathrm{eV}$ ) of a Nd:YAG was used to photodetach the cluster anions of interest. Photoelectron spectra were calibrated against the well-known atomic transitions of $\mathrm{Cu}^{-} \cdot 37$

Mixed aluminum-magnesium cluster anions were generated in a pulsed arc cluster ionization source (PACIS) that has been described in detail in Ref. 38. Briefly, a discharge is triggered between an anode and a cathode that vaporizes sample from the cathode. A copper rod was used as the anode. The cathode was prepared by pressing an aluminum and magnesium powder mixture (with the mass percentage of magnesium at $\sim 20 \%$ ) into a well on the top surface of an aluminum (cathode) rod. About 10 bars of ultra-high purity grade helium gas propelled the resultant plasma into a $20 \mathrm{~cm}$ flow tube, where the mixture cooled and formed cluster anions. The resulting cluster anions were monitored by the TOF-MS. The species of interest were then mass-selected prior to photodetachment.

\section{Computational}

Electronic structure calculations based on density functional theory were carried out on both neutral and negatively charged magnesium-aluminum clusters to identify their ground state geometries. The generalized gradient approximation (GGA) for the exchange-correlation potential and the BPW91 functional form along with 6-311+G* basis set were used for all the calculations. All the calculations were done using Gaussian03 program. ${ }^{39}$ In the geometry optimization, the convergence criterion for energy was set to $10^{-9}$ hartree, while the gradient was converged to $10^{-4}$ hartree/Å. Vibrational frequency calculations were carried out to verify the stability of these clusters. All isomers were found to have positive frequencies.

Vertical detachment energies (VDE) and adiabatic detachment energies (ADE) were calculated for the lowest energy isomers and compared with our measured VDE and electron affinity (EA) values to help evaluate the reliability of the predicted structures. The ADE is calculated to be the energy difference between the lowest energy anion and its corresponding neutral with the neutral relaxed into its nearest local minimum. The VDE is the energy difference between the 
ground state anion and its neutral counterpart at the geometry of the anion. The charge distributions in these clusters and the possibility of Zintl-characteristics were analyzed using the NPA charge analysis, as implemented in the Gaussian03 code. The fragment molecular orbital (FMO) analysis ${ }^{40}$ was carried out to verify the electron-shell closing in the aluminum moieties of the $\mathrm{Mg}_{2} \mathrm{Al}_{12}$ neutral cluster. All FMO calculations are done with the PW91 functional and the TZVP basis set on the BPW91/6-311+G* geometries using the ADF suite of the program. ${ }^{41-43}$

\section{RESULTS AND DISCUSSION}

A typical mass spectrum showing $\mathrm{Al}_{\mathrm{n}}{ }^{-}$and $\mathrm{Mg}_{m} \mathrm{Al}_{n}{ }^{-}$ cluster anions is presented in Figure 1(e). This spectrum is dominated by $\mathrm{Al}_{n}{ }^{-}$cluster anions. (The intense peak at 97 amu in Figure 1(e) is due to $\mathrm{Al}_{3} \mathrm{O}^{-}$and is not relevant to this discussion.) For ease of comparison and analysis, the $\mathrm{Al}_{\mathrm{n}}{ }^{-}, \mathrm{MgAl}_{\mathrm{n}}{ }^{-}, \mathrm{Mg}_{2} \mathrm{Al}_{\mathrm{n}}{ }^{-}$, and $\mathrm{Mg}_{3} \mathrm{Al}_{\mathrm{n}}{ }^{-}$series of cluster anions in this mass spectrum have been separated from one another and scaled to similar intensities; these can be seen in Figures 1(a)-1(d), respectively. As shown in Figure 1(a), the homogeneous aluminum cluster anions, $\mathrm{Al}_{7}{ }^{-}$and $\mathrm{Al}_{13}{ }^{-}$are prominent, showing higher intensities than their neighbors. $\mathrm{Al}_{13}$ - has been observed in many previous studies, ${ }^{44-46}$ and the intensity of this peak confirms the magicity of $\mathrm{Al}_{13}{ }^{-}$. The magicity of the $\mathrm{Al}_{7}{ }^{-}$cluster anion, however, has not been reported previously. This and other features of the mass spectrum shown in Figure 1 are routinely reproducible. Based on its high intensity, Castleman reported the enhanced stability of the $\mathrm{Al}_{7}+$ cluster cation, as observed in their mass spectrometry studies. ${ }^{46}$ Rao and Jena proposed $\mathrm{Al}_{7}{ }^{+}$to be a magic cluster with 20 valence electrons, assuming the aluminum atoms to be trivalent. ${ }^{47}$ Photoelectron spectroscopy studies on aluminum cluster anions by Wang, ${ }^{44}$ however, showed that aluminum atoms switch their valency from monovalent to trivalent at $\mathrm{n}=7$. In our mass spectrum, $\mathrm{Al}_{7}{ }^{-}$exhibits enhanced intensity compared with its neighbors and thus appears to be magic. If aluminum atoms are monovalent in $\mathrm{Al}_{7}{ }^{-}$, then this

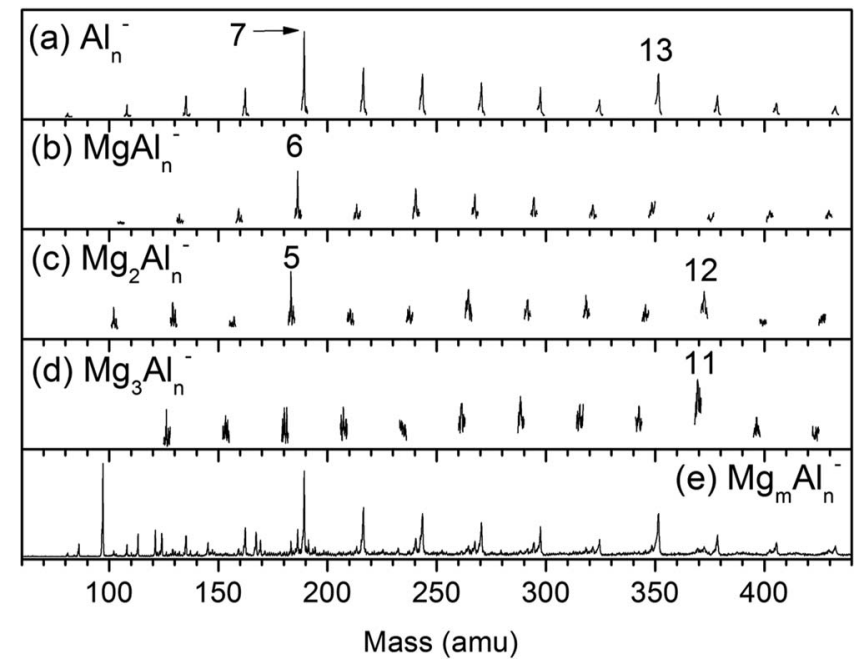

FIG. 1. Deconvoluted mass spectra showing (a) $\mathrm{Al}_{\mathrm{n}}{ }^{-}$, (b) $\mathrm{MgAl}_{\mathrm{n}}{ }^{-}$, (c) $\mathrm{Mg}_{2} \mathrm{Al}_{\mathrm{n}}{ }^{-}$, (d) $\mathrm{Mg}_{3} \mathrm{Al}_{\mathrm{n}}{ }^{-}$, and (e) full spectrum (without deconvolution). cluster anion is an eight-electron system, i.e., one of the shell closing numbers. Our mass spectrum suggests that aluminum atoms are monovalent in the case of the $\mathrm{Al}_{7}{ }^{-}$cluster anion. The apparent discrepancy between $\mathrm{Al}_{7}{ }^{+}$and $\mathrm{Al}_{7}{ }^{-}$probably just reflects the influence of charge state on the delicate balance between valencies around $n=7$ in aluminum clusters. Jena and $\mathrm{RaO}^{47}$ studied the change in the valence of $\mathrm{Al}$ in $\mathrm{Al}_{\mathrm{n}}$ clusters by monitoring the relative $s$ and $p$ content of their highest occupied molecular orbital and concluded that the transition from monovalent $\mathrm{Al}$ to trivalent $\mathrm{Al}$ can occur between $\mathrm{n}=5$ and 7 .

In the deconvoluted mass spectra of magnesium-doped, aluminum cluster anions [Figs. 1(b)-1(d)], four species appear as particularly intense peaks within the cluster series having the same numbers of magnesium atoms, i.e., in (b), (c), and (d). These are the $\mathrm{MgAl}_{6}{ }^{-}, \mathrm{Mg}_{2} \mathrm{Al}_{5}{ }^{-}, \mathrm{Mg}_{2} \mathrm{Al}_{12}{ }^{-}$, and $\mathrm{Mg}_{3} \mathrm{Al}_{11}{ }^{-}$cluster anions. In mass spectra, the relative intensities of peaks are often gauges of their ions' relative stabilities. If a cluster anion is more stable than its neighbors, it usually appears as a more intense peak. In some situations, however, even when the anion is less stable than its neighbors, it may still appear as an intense peak, if its corresponding neutral cluster is unusually stable and thus very abundant. ${ }^{48}$ Neutral $\mathrm{MgAl}_{6}$ and anionic $\mathrm{Mg}_{2} \mathrm{Al}_{5}{ }^{-}$are both closed shell species, each possessing 20 valence electrons, while the neutral $\mathrm{Mg}_{2} \mathrm{Al}_{12}$ and anionic $\mathrm{Mg}_{3} \mathrm{Al}_{11}{ }^{-}$clusters are both closed shell species with 40 electrons. In a previous mass spectrometric study, ${ }^{35}$ only $\mathrm{Mg}_{2} \mathrm{Al}_{5}{ }^{-}$and $\mathrm{Mg}_{3} \mathrm{Al}_{11}{ }^{-}$cluster anions appeared as magic species. Our ion source appears to be making not only the same closed shell cluster anions as theirs, but also somewhat more of the closed shell neutral clusters than theirs. This abundance of closed shell neutral clusters in our source leads, through electron attachment, to correspondingly prominent anion signals in our mass spectra. Thus, the apparent discrepancy is only due to different source environments.

Photoelectron spectra were collected for the four most intense mass peaks, i.e., for $\mathrm{MgAl}_{6}{ }^{-}, \mathrm{Mg}_{2} \mathrm{Al}_{5}{ }^{-}, \mathrm{Mg}_{2} \mathrm{Al}_{12}{ }^{-}$, and $\mathrm{Mg}_{3} \mathrm{Al}_{11}{ }^{-}$. Photoelectron spectra of these four anions were measured using $355 \mathrm{~nm}$ light (3.493 eV/photon), and they are presented in Figure 2. The positions of the peaks in each spectrum measure the electron binding energies (EBE) of the photodetachment transitions from the ground electronic state of that particular cluster anion to the ground and excited electronic states of that cluster anion's neutral counterpart. The EBE value at the onset (threshold) of the lowest EBE electronic transition in the spectrum gives an estimate of the electron affinity (EA) of the anion's neutral counterpart. If the ground state structures of anion and neutral clusters are similar, then the ADE corresponds to the EA of the neutral cluster. Since that is largely the case in this study, we compare ADE values with EA values. The VDE of an anionic cluster is estimated from the EBE value of the intensity maximum in the lowest EBE peak in the spectrum. The experimental EA and VDE values obtained from the photoelectron spectra are listed in Table I, where they are compared with calculated $\mathrm{ADE}$ and $\mathrm{VDE}$ values. It should be noted that the spectra of $\mathrm{MgAl}_{6}{ }^{-}, \mathrm{Mg}_{2} \mathrm{Al}_{5}{ }^{-}$, and $\mathrm{Mg}_{2} \mathrm{Al}_{12}{ }^{-}$resemble those of their isoelectronic clusters, i.e., $\mathrm{Na}_{2} \mathrm{Al}_{6}{ }^{-}, \mathrm{Na}_{4} \mathrm{Al}_{5}{ }^{-}$, and $\mathrm{Na}_{4} \mathrm{Al}_{12}{ }^{-}$, respectively. $^{32}$ 


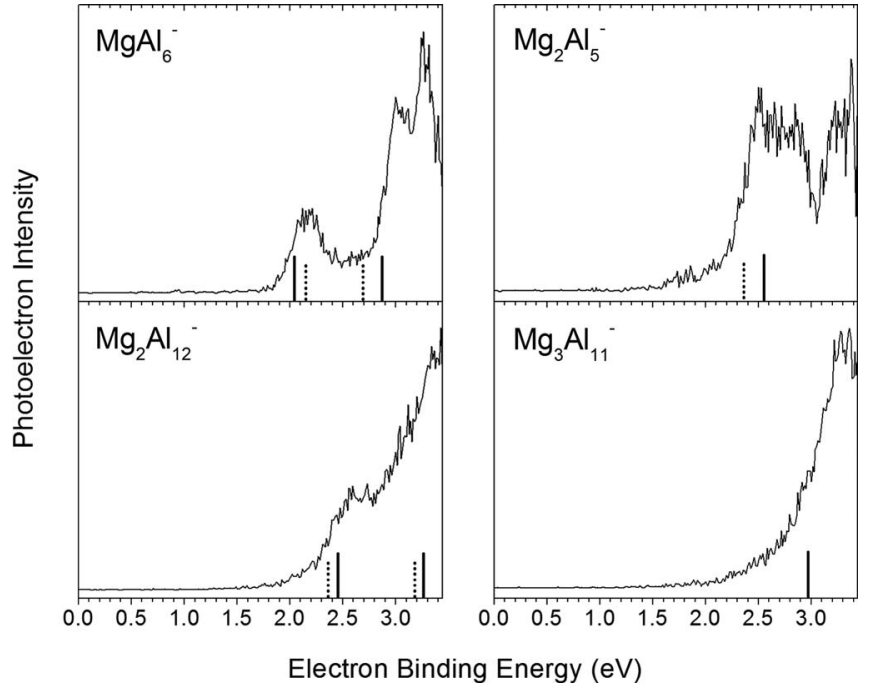

FIG. 2. Photoelectron spectra of $\mathrm{MgAl}_{6}{ }^{-}, \mathrm{Mg}_{2} \mathrm{Al}_{5}{ }^{-}, \mathrm{Mg}_{2} \mathrm{Al}_{12}{ }^{-}$, and $\mathrm{Mg}_{3} \mathrm{Al}_{11}{ }^{-}$. The stick spectra show calculated transition energies from the ground state of the anions to the ground state and excited states of corresponding neutrals at the geometries of the anions. The solid sticks correspond to transitions from the lowest energy anionic isomers, while the dotted sticks correspond to transitions from the second lowest anionic isomers.

The spectrum of the $\mathrm{MgAl}_{6}{ }^{-}$cluster anion shows a significant spacing between the first two peaks. This splitting corresponds to the gap between the highest occupied molecular orbital (HOMO) and the lowest unoccupied molecular orbital (LUMO) of the $\mathrm{MgAl}_{6}{ }^{-}$cluster anion's corresponding neutral cluster, i.e., $\mathrm{MgAl}_{6}$. The HOMO-LUMO gap of $\mathrm{MgAl}_{6}$ is measured to be $\sim 0.84 \mathrm{eV}$. A slightly smaller splitting is observed in the spectrum of the $\mathrm{Mg}_{2} \mathrm{Al}_{12}{ }^{-}$cluster anion. This is the HOMO-LUMO gap of the $\mathrm{Mg}_{2} \mathrm{Al}_{12}$ neutral cluster, and it is measured to be $\sim 0.7 \mathrm{eV}$. As expected, no distinct splitting in the lowest EBE band is observed in the spectra of the $\mathrm{Mg}_{2} \mathrm{Al}_{5}{ }^{-}$and $\mathrm{Mg}_{3} \mathrm{Al}_{11}{ }^{-}$clusters, viz., their neutral counterparts are not closed shells.

To gain a better understanding of the structure and stability of magnesium-aluminum clusters, and most importantly, to investigate the possibility of Zintl-like aluminum moieties within these magnesium-aluminum clusters, we have carried out extensive calculations based on the density functional theory. The lowest energy isomers of neutral and anionic magnesium-aluminum clusters are given in Figures 3-6. The structures of the two lowest energy isomers of the $\mathrm{MgAl}_{6}{ }^{-}$

TABLE I. Calculated and experimental electron affinities (EA), adiabatic detachment energies (ADE), and vertical detachment energies (VDE) for $\mathrm{Mg}_{\mathrm{m}} \mathrm{Al}_{\mathrm{n}}$ neutral clusters and $\mathrm{Mg}_{\mathrm{m}} \mathrm{Al}_{\mathrm{n}}{ }^{-}$cluster anions, respectively. Calculated values for the lowest energy isomers (see Figures 3-5) are listed first, with values for the next higher energy isomers listed to their right.

\begin{tabular}{lcccc}
\hline \hline & \multirow{2}{*}{$\begin{array}{c}\text { EA (eV) } \\
\text { Expt. }\end{array}$} & $\begin{array}{c}\text { ADE }(\mathrm{eV}) \\
\text { Theor. }\end{array}$ & \multicolumn{2}{c}{ VDE (eV) } \\
\cline { 3 - 5 } & 1.86 & $1.78,1.75$ & 2.16 & $2.04,2.15$ \\
\hline $\mathrm{MgAl}_{6} / \mathrm{MgAl}_{6}{ }^{-}$ & 2.15 & $2.40,2.28$ & 2.50 & $2.55,2.36$ \\
$\mathrm{Mg}_{2} \mathrm{Al}_{5} / \mathrm{Mg}_{2} \mathrm{Al}_{5}{ }^{-}$ & 2.14 & $2.01,1.92$ & 2.50 & $2.45,2.36$ \\
$\mathrm{Mg}_{2} \mathrm{Al}_{12} / \mathrm{Mg}_{2} \mathrm{Al}_{12}{ }^{-}$ & 2.81 & 2.74 & 3.28 & 2.97 \\
$\mathrm{Mg}_{3} \mathrm{Al}_{11} / \mathrm{Mg}_{3} \mathrm{Al}_{11^{-}}$ & 2.81 & & \\
\hline \hline
\end{tabular}

cluster anion (1 and 2) and of the $\mathrm{MgAl}_{6}$ neutral cluster ( $\mathbf{3}$ and 4) are presented in Figure 3 . The lowest energy isomers for both the cluster anion (1) and its neutral cluster (3) are found to be $\mathrm{Al}_{6}$ octahedra with the magnesium atom capping one of the faces of each octahedron. In both neutral and anionic cases, these octahedral-based isomers are almost energetically degenerate with the next higher energy isomer, where the $\mathrm{Al}_{6}$ moiety forms a prism with a magnesium atom capping the face of the four-member ring of the prism $(2$ and 4$)$. The structure of our calculated lowest energy isomer, $\mathbf{1}$, is in agreement with the previously reported structure of the $\mathrm{MgAl}_{6}{ }^{-}$cluster anion. ${ }^{35,49}$ In the $\mathrm{Na}_{2} \mathrm{Al}_{6}$ neutral cluster, ${ }^{32}$ which is isoelectronic to the $\mathrm{MgAl}_{6}$ neutral cluster, the $\mathrm{Al}_{6}$ moiety also preferred to form either a prism or an octahedral structure with the $\mathrm{Na}$ atoms capping the faces of the $\mathrm{Al}_{6}$ moiety. The calculated ADE and VDE values of isomers, $\mathbf{1}$ and $\mathbf{2}$ are listed in Table I along with the experimentally determined EA and VDE values. The first two transitions, corresponding to both isomers $\mathbf{1}$ and $\mathbf{2}$, respectively, were calculated and are presented as stick spectra in Figure 2. They both match well with the experimental results, suggesting that both isomers $\mathbf{1}$ and $\mathbf{2}$ are observed in the experiment.

Although the electronegativity of magnesium and aluminum are similar, namely 1.31 and 1.61 on the Pauling scale, respectively, the lower value for magnesium suggests an opportunity for partial electron transfer from magnesium atom(s) to the aluminum moiety. To explore this, NPA charge analysis was carried out for both neutral $\mathrm{MgAl}_{6}$ and $\mathrm{MgAl}_{6}{ }^{-}$ anionic clusters. In the neutral $\mathrm{MgAl}_{6}$ cluster, the magnesium atom donates only -0.61 e to the $\mathrm{Al}_{6}$ moiety in isomer $\mathbf{3}$, while in the case of the isomer 4 , a charge transfer of $-0.56 e$ was found. This shows that there is a partial charge transfer from magnesium atom, but it also shows that the $\mathrm{Al}_{6}$ moiety does not exhibit Zintl anion character in this cluster. It is noteworthy that in the case of the isoelectronic $\mathrm{Na}_{2} \mathrm{Al}_{6}$ cluster, ${ }^{32}$ a significant amount of charge transfer $(-1.54 e)$ was found to occur from the sodium atoms to its $\mathrm{Al}_{6}$ moiety. This difference in the charge transfer is due to the fact that, while the electronegativities of magnesium and aluminum atoms are similar, the electronegativity of sodium ( 0.93 on the Pauling scale) is significantly lower than that of magnesium.

When an extra electron is added to the $\mathrm{MgAl}_{6}$ neutral cluster to form the $\mathrm{MgAl}_{6}{ }^{-}$cluster anion, the majority of the electron's charge goes to the $\mathrm{Al}_{6}$ moiety, which already has a negative charge. In the lowest energy isomer, $64.4 \%$ of the electron's charge is spread over the $\mathrm{Al}_{6}$ moiety, increasing its net charge from $-0.61 e$ to $-1.25 e$. In the case of the isomer 2 , about $82.1 \%$ of the extra electron's charge goes to the $\mathrm{Al}_{6}$ prism, thereby increasing the charge on the $\mathrm{Al}_{6}$ from $-0.56 \mathrm{e}$ to $-1.38 e$. Even though majority of the extra electron's charge is located on the $\mathrm{Al}_{6}$, the aluminum moiety in isomer $\mathbf{2}$ of the $\mathrm{MgAl}_{6}{ }^{-}$cluster anion does not exhibit strong Zintl anion character, as it does in the case of its isoelectronic counterpart, i.e., the $\mathrm{Na}_{2} \mathrm{Al}_{6}{ }^{-}$cluster anion. ${ }^{32}$

In the cases of both the $\mathrm{Mg}_{2} \mathrm{Al}_{12}$ neutral and the $\mathrm{Mg}_{2} \mathrm{Al}_{12}{ }^{-}$anionic clusters, two nearly iso-energetic isomers were also found (see Figure 4). In the lowest energy isomer of the $\mathrm{Mg}_{2} \mathrm{Al}_{12}{ }^{-}$cluster anion (5), one of the magnesium atoms occupies the vertex site of an $\mathrm{MgAl}_{12}$ icosahedron-like 


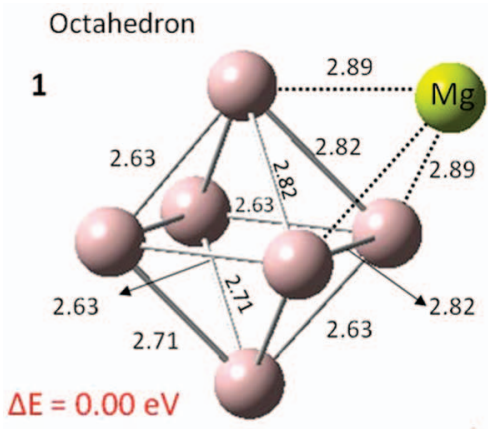

$1 \mathrm{Mg}:+0.255 e, 6 \mathrm{Al}:-1.255 e$

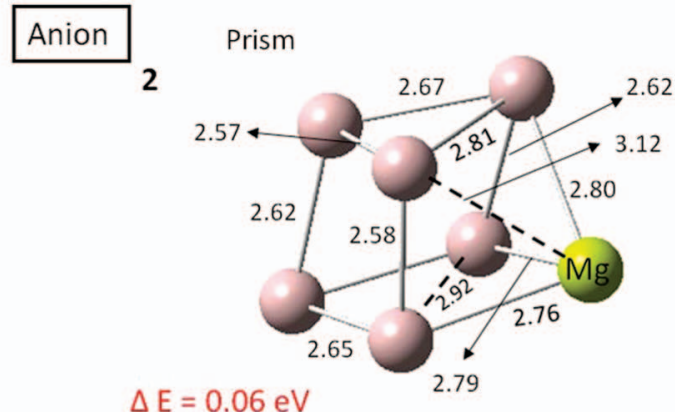

$1 \mathrm{Mg}:+0.385 e, 6 \mathrm{Al}:-1.385 e$

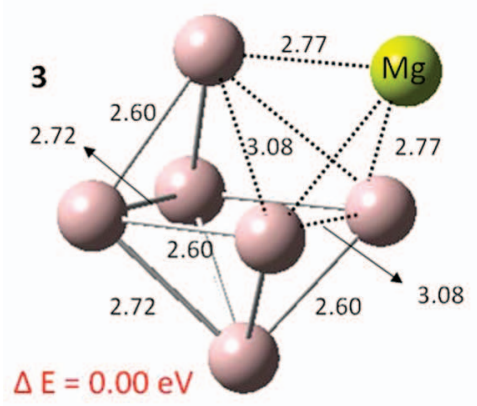

$1 \mathrm{Mg}:+0.611 e, 6 \mathrm{Al}:-0.611 e$
Neutral

\section{4}

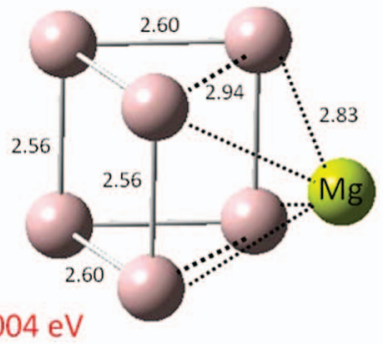

$1 \mathrm{Mg}:+0.564 e, 6 \mathrm{Al}:-0.564 e$

FIG. 3. The two lowest energy structures of both $\mathrm{MgAl}_{6}{ }^{-}$anionic and $\mathrm{MgAl}_{6}$ neutral clusters are shown along with their relative energies, $\Delta \mathrm{E}$ (eV). The green sphere represents magnesium atom. All the bond lengths are given in $\AA$. The calculated Natural Population Analysis (NPA) charges are given in the italics below each isomer.
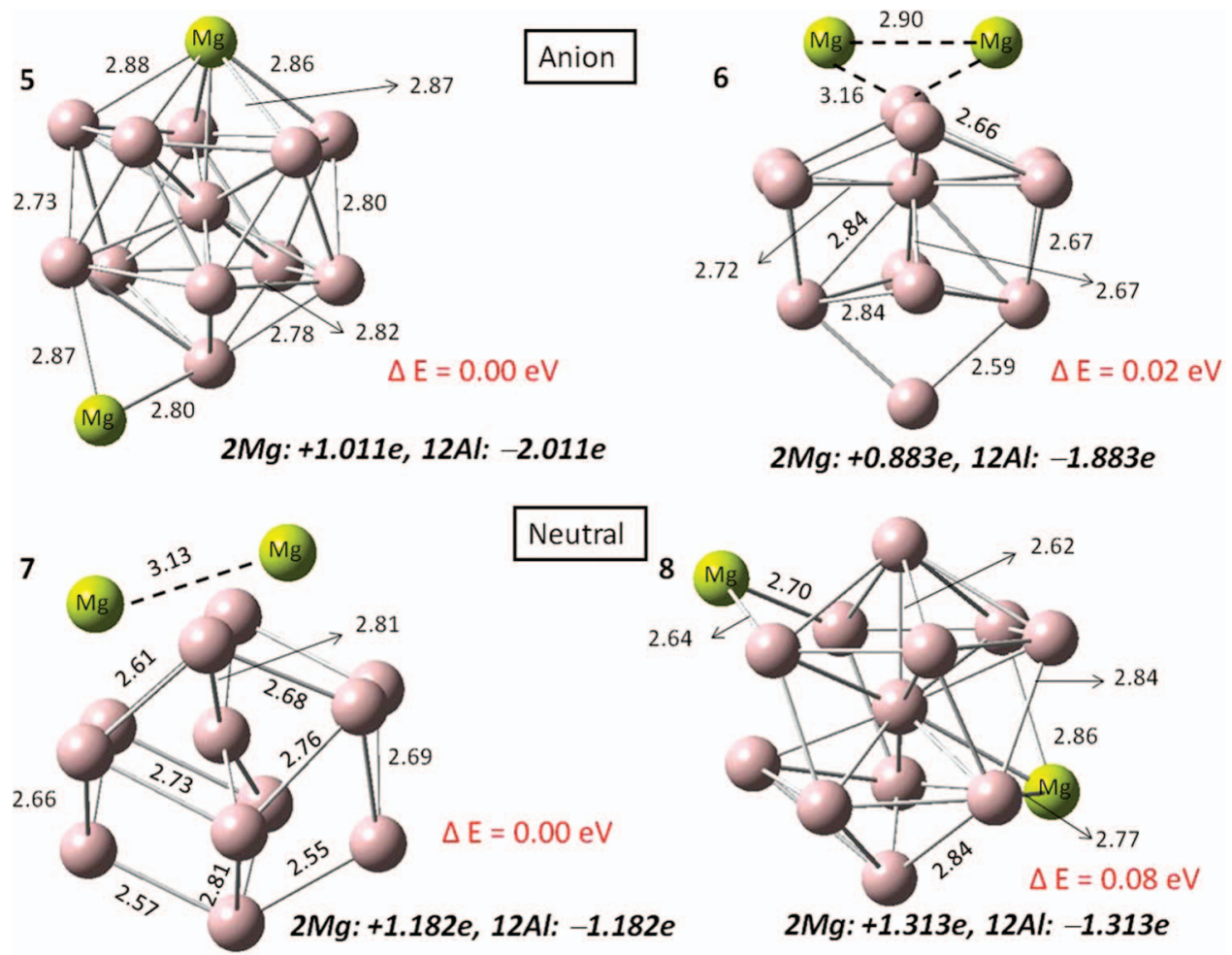

FIG. 4. The two lowest energy structures of both $\mathrm{Mg}_{2} \mathrm{Al}_{12}{ }^{-}$anionic and $\mathrm{Mg}_{2} \mathrm{Al}_{12}$ neutral clusters are shown along with the relative energies, $\Delta \mathrm{E}$ (eV). The green spheres represent magnesium atoms. All the bond lengths are given in $\AA$. The calculated Natural Population Analysis (NPA) charges are given in the italics below each isomer. 


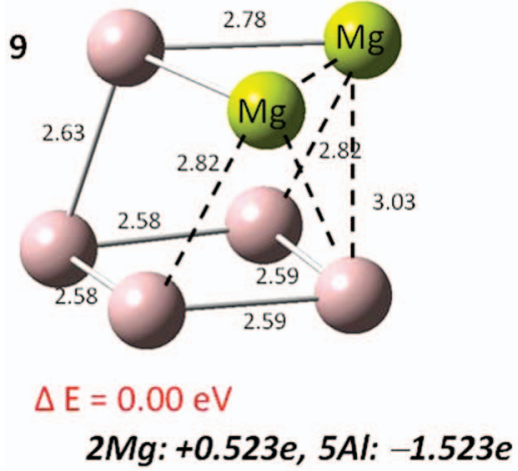

$2 \mathrm{Mg}:+0.523 e, 5 \mathrm{Al}:-1.523 e$

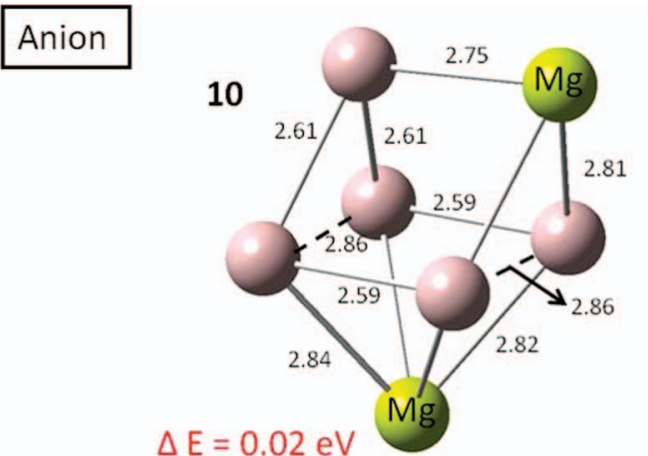

2Mg: +0.747e, 5Al: $-1.747 e$

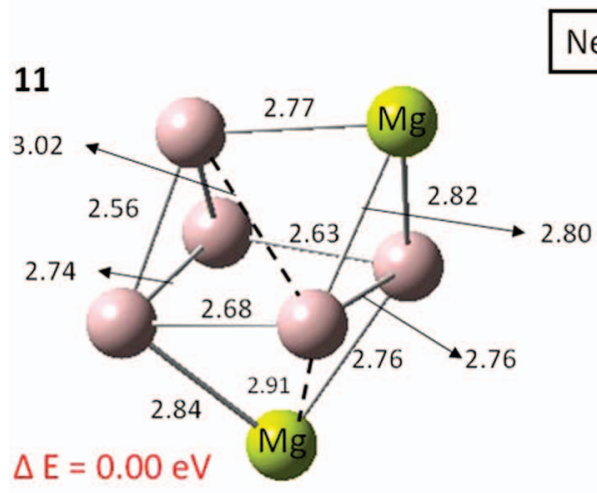

2Mg: +1.191e, 5Al: $-1.191 e$

Neutral

12

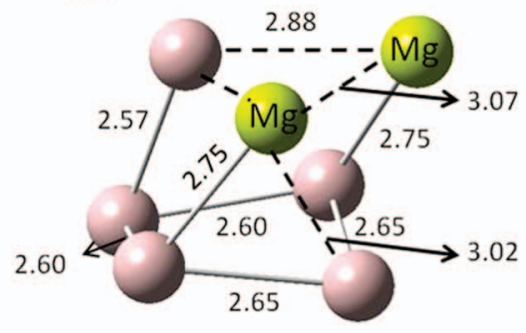

$\Delta \mathrm{E}=0.09 \mathrm{eV}$

$2 M g:+0.912 e, 5 A l:-0.912 e$

FIG. 5. The two lowest energy structures of both $\mathrm{Mg}_{2} \mathrm{Al}_{5}{ }^{-}$anionic and $\mathrm{Mg}_{2} \mathrm{Al}_{5}$ neutral clusters are shown along with the relative energies, $\Delta \mathrm{E}$ (eV). The green spheres represent magnesium atoms. All the bond lengths are given in $\AA$. The calculated Natural Population Analysis (NPA) charges are given in the italics below each isomer.

sub-structure, as if it is replacing an $\mathrm{Al}$ atom in an $\mathrm{Al}_{13}$ icosahedron, while the other magnesium atom caps one of the faces of this icosahedron. An analogous situation was reported ${ }^{50}$ upon doping magnesium atoms into $\mathrm{SrAl}_{2}$, where the dopant magnesium atom preferred to occupy the aluminum site, resulting in $\operatorname{Sr}\left(\mathrm{Al}_{1-\mathrm{x}} \mathrm{Mg}_{\mathrm{x}}\right)_{2}$. In the second lowest isomer (6) $(\Delta \mathrm{E}$ $=0.02 \mathrm{eV}), 12$ aluminum atoms form a compact cluster, while the two magnesium atoms bond together and cap the two adjacent $\mathrm{Al}_{4}$ faces of the $\mathrm{Al}_{12}$ cluster. The lowest energy isomer

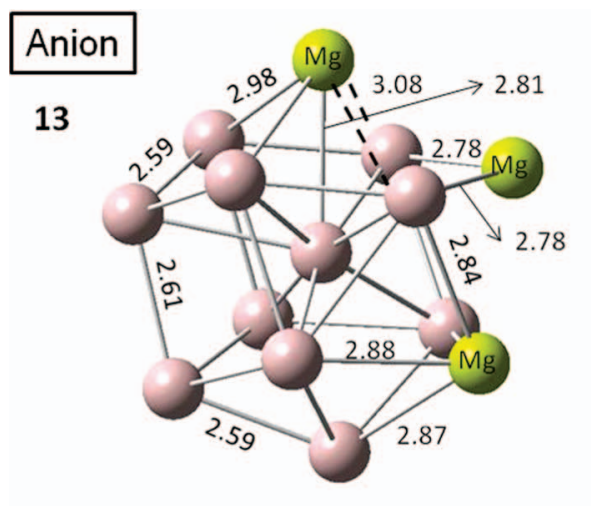

$3 M g:+1.384 e, 11 \mathrm{Al}:-2.384 e$ of the neutral $\mathrm{Mg}_{2} \mathrm{Al}_{12}$ cluster (7), on the other hand, is similar to the second lowest structure of the anion $(\mathbf{6})$, where the two magnesium atoms cap the adjacent faces of the $\mathrm{Al}_{12}$ cluster. Interestingly, in isomer (7), the distance between the two magnesium atoms has increased to $3.13 \AA$ from $2.90 \AA$ in the anionic cluster structure, (6). This is due to the fact that in the anionic cluster (6), the magnesium atoms each have a charge of $+0.44 e$, while in the case of the neutral cluster (7), the charge on each of the magnesium atoms is $+0.59 e$;

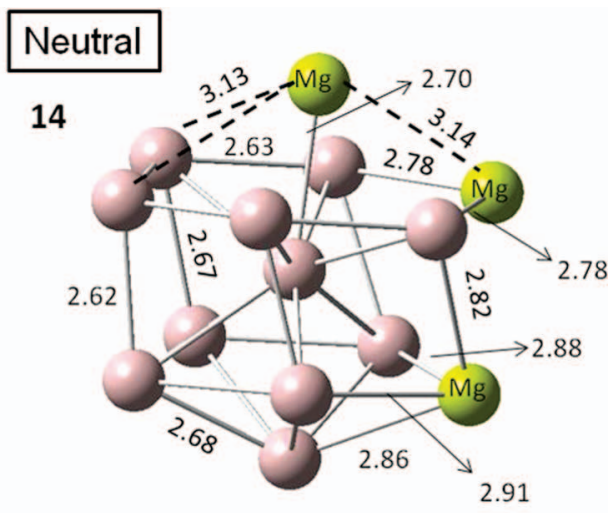

3Mg: +1.79e, 11Al: $-1.79 e$

FIG. 6. The lowest energy structures of both $\mathrm{Mg}_{3} \mathrm{Al}_{11}{ }^{-}$anionic and $\mathrm{Mg}_{3} \mathrm{Al}_{11}$ neutral clusters are shown. The green spheres represent magnesium atoms. All the bond lengths are given in A. The calculated Natural Population Analysis (NPA) charges are given in the italics below each isomer. 
thereby increasing the repulsive interaction between them and leading to an increase in the distance between the two magnesium atoms. In the icosahedron-like structure $(\mathbf{8})$, which is $0.08 \mathrm{eV}$ higher in energy than isomer (7), one of the magnesium atoms again forms a part of the icosahedron, while the other magnesium atom is attached to $\mathrm{MgAl}_{12}$ icosahedron. The calculated VDE values of isomers $5(2.45 \mathrm{eV})$ and $6(2.36 \mathrm{eV})$ are in good agreement with the measured VDE of $2.50 \mathrm{eV}$ (see Table I). The calculated higher energy transitions corresponding to each isomer are also shown in Figure 2 as stick spectra. Comparison between experimental and computational results indicates that both isomers $\mathbf{5}$ and $\mathbf{6}$ appear to be contributing to the photoelectron spectrum.

To determine whether the $\mathrm{Al}_{12}$ moiety is multiply charged, we have carried out NPA charge analyses for both the $\mathrm{Mg}_{2} \mathrm{Al}_{12}$ neutral and the $\mathrm{Mg}_{2} \mathrm{Al}_{12}{ }^{-}$anionic clusters. In the neutral $\mathrm{Mg}_{2} \mathrm{Al}_{12}$ cluster, both magnesium atoms together donate a net charge to the $\mathrm{Al}_{12}$ moiety of $-1.18 e$ (for isomer 7) and $-1.31 e$ (for isomer 8). Thus, as in the previous case, there is only limited charge transfer $(\Delta \mathrm{Q} \sim-0.59 e$ to $-0.65 e$ per $\mathrm{Mg}$ atom) in this cluster; the $\mathrm{Al}_{12}$ moiety in the $\mathrm{Mg}_{2} \mathrm{Al}_{12}$ neutral cluster does not exhibit a strong Zintl anion character. Again, this is in contrast with the previously reported ${ }^{32}$ isoelectronic $\mathrm{Na}_{4} \mathrm{Al}_{12}$ neutral cluster, where its $\mathrm{Al}_{12}$ moiety, with a charge of $-3.43 e$, shows strong Zintl anion character. Upon the addition of an extra electron to the $\mathrm{Mg}_{2} \mathrm{Al}_{12}$ cluster to from its cluster anion, the charge on $\mathrm{Al}_{12}$ moiety increased from $-1.18 e$ (in isomer 7) to $-2.01 e$ (in isomer $\mathbf{5}$ ) and from $-1.31 e$ (in isomer 8) to $-1.88 e$ (in isomer 6). Thus, in the case of the $\mathrm{Mg}_{2} \mathrm{Al}_{12}{ }^{-}$cluster anion, its $\mathrm{Al}_{12}$ moiety shows significant Zintl anion character.

The two lowest energy isomers of both the $\mathrm{Mg}_{2} \mathrm{Al}_{5}{ }^{-}$ cluster anion and the $\mathrm{Mg}_{2} \mathrm{Al}_{5}$ neutral cluster are presented in Figure 5. The lowest energy anionic structure, (9), can be seen as an $\mathrm{Mg}_{2} \mathrm{Al}$ triangle held parallel to an $\mathrm{Al}_{4}$ plane. In the second lowest energy $(\Delta \mathrm{E}=0.02 \mathrm{eV})$ anionic isomer (10), five aluminum atoms and one magnesium atom form a prism-like structure, while the other magnesium atom caps the $\mathrm{Al}_{4}$ face of the prism. In isomer 10, there is no interaction between the magnesium atoms, while there is in isomer $\mathbf{9}$. The lowest energy structure (isomer 9) is in agreement with the previously reported structure of the $\mathrm{Mg}_{2} \mathrm{Al}_{5}{ }^{-}$cluster anion. ${ }^{35}$ In the neutral $\mathrm{Mg}_{2} \mathrm{Al}_{5}$ cluster, similarly to what was seen in $\mathrm{Mg}_{2} \mathrm{Al}_{12}$ cluster, the structure of the higher energy isomer (12) resembles that of the lowest energy anionic isomer (9), while the structure of the lowest energy neutral isomer (11) resembles that of the higher energy anionic isomer (10). The calculated VDE values of isomer $\mathbf{9}$ and $\mathbf{1 0}$ are 2.55 and $2.36 \mathrm{eV}$, respectively (see Table I). These values are in good agreement with the measured value of $2.50 \mathrm{eV}$, indicating the possibility that the two isomers co-exist in the experiment.

The structures of the lowest energy isomers of the $\mathrm{Mg}_{3} \mathrm{Al}_{11}{ }^{-}$cluster anion and the $\mathrm{Mg}_{3} \mathrm{Al}_{11}$ neutral cluster are shown in Figure 6. In both the $\mathrm{Mg}_{3} \mathrm{Al}_{11}{ }^{-}$cluster anion (13) and the neutral $\mathrm{Mg}_{3} \mathrm{Al}_{11}$ cluster (14), the three magnesium atoms are embedded in the $\mathrm{Al}_{11}$ moiety, resulting in rhombohedral-like structures. In these structures, one of the magnesium atoms occupies the apex site, while of the two remaining magnesium atoms, one of them forms part of the five- member ring $\left(\mathrm{MgAl}_{4}\right)$, and the other caps the $\mathrm{Al}_{5}$ ring. Note that the isoelectronic $\mathrm{Na}_{4} \mathrm{Al}_{12}$ and $\mathrm{Na}_{3} \mathrm{Al}_{12}{ }^{-}$clusters were also shown ${ }^{32}$ to exhibit a rhombohedral-like structure with a sodium atom occupying the vertex-site. However, unlike the $\mathrm{Na}_{4} \mathrm{Al}_{12}$ neutral and the $\mathrm{Na}_{3} \mathrm{Al}_{12}{ }^{-}$anionic clusters, where the remaining sodium atoms merely cap the $\mathrm{Al}_{12}$ moiety, in the $\mathrm{Mg}_{3} \mathrm{Al}_{11}$ - cluster anion, the magnesium atoms form an integral part of the $\mathrm{Al}_{11}$ moiety. This is due to the similar electronegativity values of magnesium (1.31) and aluminum (1.61) atoms as well as the similar atomic sizes of magnesium and aluminum atoms. The calculated VDE $(2.97 \mathrm{eV})$ and $\mathrm{ADE}(2.74 \mathrm{eV})$ values for the $\mathrm{Mg}_{3} \mathrm{Al}_{11}{ }^{-}$cluster anion are in reasonable agreement with the measured VDE and EA values of 3.28 and $2.81 \mathrm{eV}$, respectively, thus validating the calculated structures.

While our charge analyses found only limited charge transfer to the aluminum moieties of the $\mathrm{MgAl}_{6}, \mathrm{Mg}_{2} \mathrm{Al}_{12}$, and $\mathrm{Mg}_{2} \mathrm{Al}_{5}$ neutral clusters and their corresponding cluster anions, both the $\mathrm{Mg}_{3} \mathrm{Al}_{11}$ neutral cluster and the $\mathrm{Mg}_{3} \mathrm{Al}_{11}{ }^{-}$ cluster anion exhibited significant charge transfer to their $\mathrm{Al}_{11}$ moieties. In the case of the $\mathrm{Mg}_{3} \mathrm{Al}_{11}$ neutral cluster (14), its $\mathrm{Al}_{11}$ moiety holds $-1.79 e$ of negative charge, making it a Zintl anion, whereas in the case of the $\mathrm{Mg}_{3} \mathrm{Al}_{11}{ }^{-}$cluster anion, its $\mathrm{Al}_{11}$ moiety possesses $-2.38 e$ of negative charge. The $\mathrm{Al}_{11}$ moieties in both charge states clearly have significant Zintl anion character. Thus, the formation of aluminum Zintl anion moieties in magnesium-aluminum clusters is feasible when the magnesium content is relatively high. The Cartesian coordinates of all the optimized geometries of clusters discussed above are given in the supplementary material. ${ }^{51}$

To better understand the similarities and differences between sodium-aluminum and magnesium-aluminum clusters, we have constructed comparative valence FMO diagrams for the isoelectronic $\mathrm{Mg}_{2} \mathrm{Al}_{12}$ and $\mathrm{Na}_{4} \mathrm{Al}_{12}$ neutral clusters (see Figure 7). Both of these FMO diagrams utilize 40 valence electrons (in 20 molecular orbitals), forming four distinct blocks of energy levels. Further examination reveals that these blocks correspond to $1 \mathrm{~S} ; 1 \mathrm{P} ; 1 \mathrm{D} / 2 \mathrm{~S}$; and $1 \mathrm{~F} / 2 \mathrm{P}$ shells; thereby, confirming the 40-electron shell closing in both these clusters. However, despite the similarities between the overall distributions of the valence electrons, there are also significant differences between them and the clusters they represent. The $\mathrm{Mg} 3 s^{2}$ orbital is located between the $\mathrm{Al} 3 s^{2}$ and $3 p^{1}$ orbitals, whereas the $\mathrm{Na} 3 s^{1}$ orbital energy is close to that of the $\mathrm{Al} 3 p^{1}$. As a result, there is a considerable overlap between magnesium and aluminum orbitals and less charge transfer. On the other hand, the interaction between sodium and aluminum is mostly electrostatic with a little orbital overlap. These interactions are consistent with the NPA charge analyses of these clusters. As expected, all valence molecular orbitals of $\mathrm{Na}_{4} \mathrm{Al}_{12}$ are significantly moved up in energy compared to the corresponding $\mathrm{Mg}_{2} \mathrm{Al}_{12}$ levels. This is a result of larger charge accumulation on the $\mathrm{Al}_{12}$ core in the sodium-aluminum cluster $(-3.43 e)$ compared with that in the magnesium-aluminum cluster $(-1.18 e)$. Similar results were also obtained in the comparison of $\mathrm{Na}_{2} \mathrm{Al}_{6}$ and $\mathrm{MgAl}_{6}$ neutral clusters. Clearly, magnesium-aluminum bonding is more covalent and less ionic than sodium-aluminum bonding. 

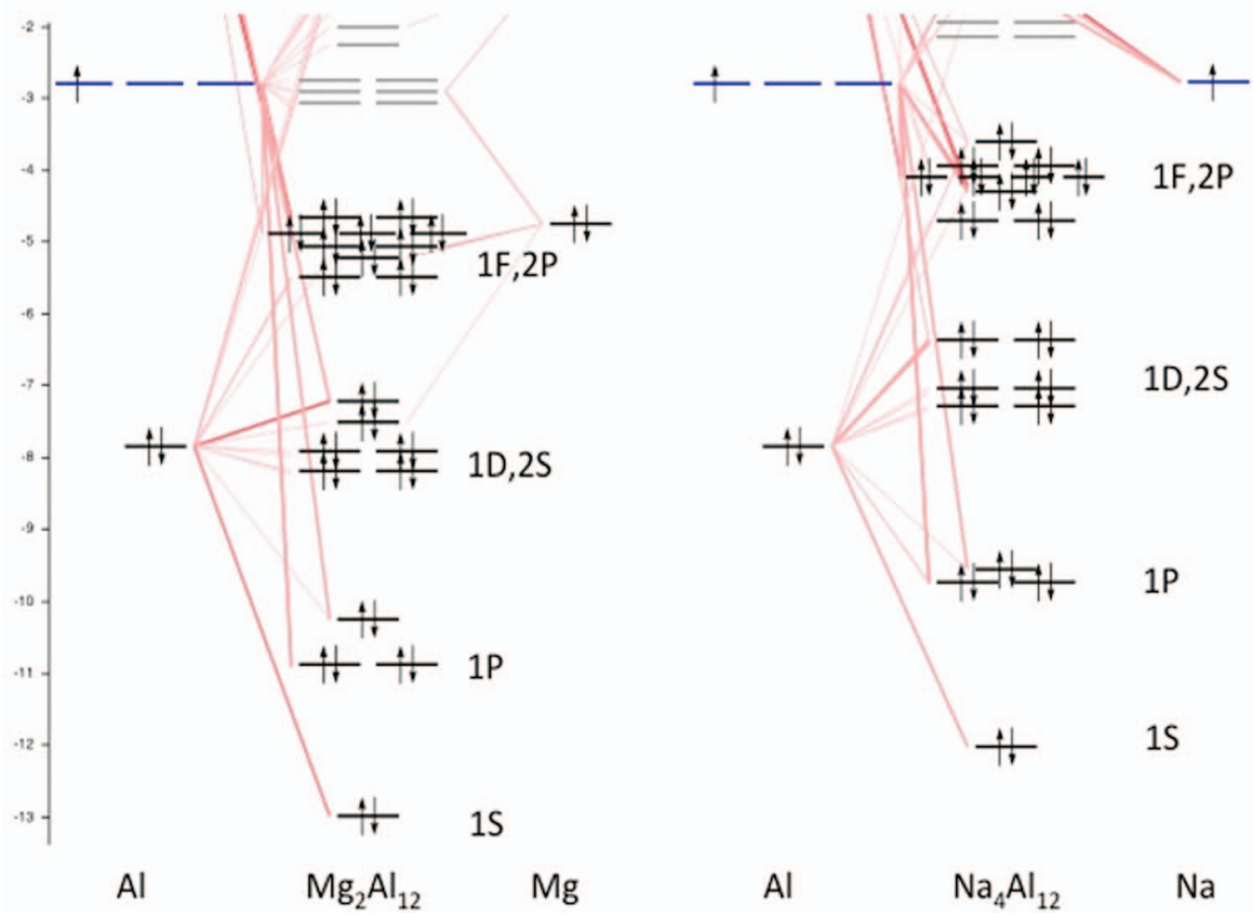

FIG. 7. A comparative fragment molecular orbitals (FMO) analysis of the $\mathrm{Mg}_{2} \mathrm{Al}_{12}$ neutral cluster versus the $\mathrm{Na}_{4} \mathrm{Al}_{12}$ neutral cluster.

\section{SUMMARY}

A combined theoretical and experimental study was carried out on magnesium aluminum clusters and their anions. Anion mass spectrometry found $\mathrm{Al}_{7}{ }^{-}, \mathrm{Al}_{13}{ }^{-}, \mathrm{MgAl}_{6}{ }^{-}$, $\mathrm{Mg}_{2} \mathrm{Al}_{5}{ }^{-}, \mathrm{Mg}_{2} \mathrm{Al}_{12}{ }^{-}$, and $\mathrm{Mg}_{3} \mathrm{Al}_{11}{ }^{-}$to be prominent peaks. The enhanced stability of $\mathrm{Al}_{7}{ }^{-}$and $\mathrm{Al}_{13}{ }^{-}$can be explained by shell closure at 8 and 40 electrons. Similarly, the enhanced stability of $\mathrm{MgAl}_{6}{ }^{-}, \mathrm{Mg}_{2} \mathrm{Al}_{5}{ }^{-}, \mathrm{Mg}_{2} \mathrm{Al}_{12}{ }^{-}$, and $\mathrm{Mg}_{3} \mathrm{Al}_{11}{ }^{-}$ cluster anions can be explained by shell closures with 20 or 40 valence electrons in either the neutral or the anion species in each case. Most importantly, unlike their isoelectronic $\mathrm{Na}_{m} \mathrm{Al}_{n}$ counterparts, only a limited charge transfer occurred between the magnesium and aluminum atoms in most $\mathrm{Mg}_{m} \mathrm{Al}_{n}$ cluster stoichiometries. Our calculations have shown that in order for $\mathrm{Al}_{n}$ moieties within magnesium-aluminum clusters to exhibit Zintl anion character, relatively high magnesium content is required. Clearly, aluminum needs an appropriately low electronegativity partner in order for aluminum Zintl anions to form readily in its clusters. Perhaps, super-alkali molecules ${ }^{52}$ should be explored as potentially optimal partners with aluminum for forming ionic lattices consisting of aluminum Zintl anions and counter-cations.

\section{ACKNOWLEDGMENTS}

This material is based in part on work supported by the Air Force Office of Scientific Research (AFOSR) under Grant No. FA9550-11-1-0068 (K.H.B.) and FA9550-111-0171 (B.W.E.). Both K.H.B. and B.W.E. thank the Defense Threat Reduction Agency (DTRA) for partial support of this work under Grant No. HDTRA-1-12-1-007. B.K. acknowledges financial support from the BoR-RCS grant. P.J. ac- knowledges supported by the U.S. Department of Energy, Office of Basic Energy Sciences, Division of Materials Sciences and Engineering under Award No. DE-FG02-96ER45579.

${ }^{1}$ H. W. Kroto, J. R. Heath, S. C. O'Brien, R. F. Curl, and R. E. Smalley, Nature (London) 318, 162-163 (1985).

${ }^{2}$ B. C. Guo, K. P. Kerns, and A. W. Castleman, Science 255, 1411 (1992).

${ }^{3}$ B. C. Guo, S. Wei, J. Purnell, S. Buzza, and A. W. Castleman, Science 256, 515 (1992).

${ }^{4}$ S. N. Khanna and P. Jena, Phys. Rev. Lett. 69, 1664 (1992).

${ }^{5}$ D. E. Bergeron, P. J. Roach, A. W. Castleman, N. Jones, and S. N. Khanna, Science 307, 231 (2005).

${ }^{6}$ S. N. Khanna and P. Jena, Phys. Rev. B 51, 13705 (1995).

${ }^{7}$ F. Liu, M. Mostoller, T. Kaplan, S. N. Khanna, and P. Jena, Chem. Phys. Lett. 248, 213 (1996).

${ }^{8}$ S. N. Khanna, B. K. Rao, and P. Jena, Phys. Rev. B 65, 125105 (2002).

${ }^{9}$ W. J. Zheng, O. C. Thomas, T. P. Lippa, S. J. Xu, and K. H. Bowen, J. Chem. Phys. 124, 144304 (2006).

${ }^{10}$ A. Nakajima, K. Hoshino, T. Sugioka, T. Naganuma, T. Taguwa, Y. Yamada, K. Watanabe, and K. Kaya, J. Phys. Chem. 97, 86 (1993).

${ }^{11}$ K. Hoshino, K. Watanabe, Y. Konishi, T. Taguwa, A. Nakajima, and K. Kaya, Chem. Phys. Lett. 231, 499 (1994).

${ }^{12}$ E. Zintl, J. Goubeau, and W. Dullenkopf, Z. Phys. Chem., Abt. A 154, 1 (1931).

${ }^{13}$ E. Zintl and A. Harder, Z. Phys. Chem., Abt. A 154, 47 (1931).

${ }^{14}$ E. Zintl and W. Dullenkopf, Z. Phys. Chem., Abt. B 16, 183 (1932).

${ }^{15}$ E. Zintl, Angew. Chem. 52, 1 (1939).

${ }^{16} \mathrm{~F}$. Laves, Naturwissenschaften 29, 244 (1941).

${ }^{17}$ W. Klemm and E. Busmann, Z. Anorg. Allg. Chem. 319, 297 (1963).

${ }^{18}$ J. D. Corbett, Chem. Rev. 85, 383 (1985).

${ }^{19}$ R. W. Farley and A. W. Castleman, J. Am. Chem. Soc. 111, 2734 (1989).

${ }^{20}$ R. W. Farley and A. W. Castleman, J. Chem. Phys. 92, 1790 (1990).

${ }^{21}$ W. J. Zheng, O. C. Thomas, J. M. Nilles, K. H. Bowen, A. C. Reber, and S. N. Khanna, J. Chem. Phys. 134, 224307 (2011).

${ }^{22}$ A. E. Kuznetsov, A. I. Boldyrev, X. Li, and L. S. Wang, J. Am. Chem. Soc. 123, 8825 (2001).

${ }^{23}$ L. F. Cui, X. Huang, L. M. Wang, D. Y. Zubarev, A. I. Boldyrev, J. Li, and L. S. Wang, J. Am. Chem. Soc. 128, 8390 (2006).

${ }^{24}$ L. F. Cui, X. Huang, L. M. Wang, J. Li, and L. S. Wang, J. Phys. Chem. A 110, 10169 (2006). 
${ }^{25}$ X. Li, A. E. Kuznetsov, H.-F. Zhang, A. I. Boldyrev, and L. S. Wang, Science 291, 859 (2001).

${ }^{26}$ A. E. Kuznetsov, K. A. Birch, A. I. Boldyrev, X. Li, H. J. Zhai, and L. S. Wang, Science 300, 622 (2003).

${ }^{27}$ A. E. Kuznetsov, A. I. Boldyrev, H. J. Zhai, X. Li, and L. S. Wang, J. Am. Chem. Soc. 124, 11791 (2002).

${ }^{28}$ O. C. Thomas, W. J. Zheng, T. P. Lippa, S. J. Xu, and K. H. Bowen, J. Chem. Phys. 114, 9895 (2001).

${ }^{29}$ O. C. Thomas, W. J. Zheng, and K. H. Bowen, J. Chem. Phys. 114, 5514 (2001).

${ }^{30}$ Y. J. Ko, A. Shakya, H. Wang, A. Grubisic, W. J. Zheng, M. Gotz, G. Gantefoer, K. H. Bowen, P. Jena, and B. Kiran, J. Chem. Phys. 133, 124308 (2010).

${ }^{31}$ N. Walsh, F. Martinez, G. Marx, and L. Schweikhard, Eur. Phys. J. D 43, 241 (2007).

${ }^{32}$ H. Wang, X. Zhang, Y. J. Ko, A. Grubisic, X. Li, G. Gantefoer, H. Schnoeckel, B. W. Eichhorn, M.-S. Lee, P. Jena, A. K. Kandalam, B. Kiran, and K. H. Bowen, J. Chem. Phys. 140, 054301 (2014).

${ }^{33}$ O. C. Thomas, W.-J. Zheng, S.-J. Xu, and K. H. Bowen, Phys. Rev. Lett. 89, 213403 (2002).

${ }^{34}$ T. Diederich, T. Doppner, T. Fennel, J. Tiggesbaumker, and K. H. MeiwesBroer, Phys. Rev. A 72, 023203 (2005).

${ }^{35}$ Z. Luo, C. J. Grover, A. C. Reber, S. N. Khanna, and A. W. Castleman, Jr., J. Am. Chem. Soc. 135, 4307 (2013).

${ }^{36}$ M. Gerhards, O. C. Thomas, J. M. Nilles, W. J. Zheng, and K. H. Bowen, J. Chem. Phys. 116, 10247 (2002)

${ }^{37}$ J. Ho, K. M. Ervin, and W. C. Lineberger, J. Chem. Phys. 93, 6987 (1990).

${ }^{38}$ X. Li, A. Grubisic, S. T. Stokes, J. Cordes, G. F. Gantefoer, K. H. Bowen, B. Kiran, M. Willis, P. Jena, R. Burgert, and H. Schnoeckel, Science 315, 356 (2007).
${ }^{39}$ M. J. Frisch, G. W. Trucks, H. B. Schlegel et al., GAUSSIAN 03, Revision C.02, Gaussian, Inc., Wallingford, CT, 2004.

${ }^{40}$ F. M. Bickelhaupt and E. J. Baerends, in Reviews in Computational Chemistry, edited by K. B. Lipkowitz and D. B. Boyd (Wiley, New York, 2000), Vol. 15, pp. 1-86.

${ }^{41}$ G. te Velde, F. M. Bickelhaupt, S. J. A. van Gisbergen, C. Fonseca Guerra, E. J. Baerends, J. G. Snijders, and T. Ziegler, J. Comput. Chem. 22, 931 (2001).

${ }^{42}$ C. Fonseca Guerra, J. G. Snijders, G. te Velde, and E. J. Baerends, "Towards an order-N DFT method," Theor. Chem. Acc. 99, 391 (1998).

${ }^{43}$ SCM, Theoretical Chemistry, ADF2013, Vrije Universiteit, Amsterdam, The Netherlands, 2013, see http://www.scm.com.

${ }^{44}$ X. Li, H. Wu, X. B. Wang, and L. S. Wang, Phys. Rev. Lett. 81, 1909 (1998).

${ }^{45}$ R. E. Leuchtner, A. C. Harms, and A. W. Castleman, J. Chem. Phys. 91, 2753 (1989)

${ }^{46}$ R. E. Leuchtner, A. C. Harms, and A. W. Castleman, J. Chem. Phys. 94, 1093 (1991)

${ }^{47}$ B. K. Rao and P. Jena, J. Chem. Phys. 111, 1890 (1999).

${ }^{48}$ A. W. Castleman, S. N. Khanna, A. Sen, A. C. Reber, M. Qian, K. M. Davis, S. J. Peppernick, A. Ugrinov, and M. D. Merritt, Nano Lett. 7, 2734 (2007).

${ }^{49}$ Y. Ouyang, P. Wang, P. Xiang, H. Chen, and Y. Du, Comput. Theor. Chem. 984, 68 (2012)

${ }^{50}$ Q. A. Zhang and E. Akiba, J. Alloys Compd. 360, 143 (2003).

${ }^{51}$ See supplementary material at http://dx.doi.org/10.1063/1.4869104 for the Cartesian coordinates of the optimized geometries of all the clusters discussed here.

${ }^{52}$ D. Wang, J. D. Graham, A. M. Buytendyk, and K. H. Bowen, J. Chem. Phys. 135, 164308 (2011). 